\title{
A COMPREENSÃO DA PRÁTICA EDUCATIVA DE UM MUSEU NA PERSPECTIVA DAS COMUNIDADES DE PRÁTICA
}

\section{RESUMO:}

Este texto discute a dinâmica de constituição das práticas realizadas pelos educadores do setor educativo de um museu de ciência na perspectiva das Comunidades de Práticas de Etienne Wenger. $O$ universo de estudo foi a área educativa do Museu Paraense Emílio Goeldi e os dados foram analisados com base nas categorias de engajamento mútuo, empreendimento conjunto e repertório partilhado. Verificou-se que a área educativa deste museu se estrutura parcialmente como uma comunidade de prática de educação em museus. As análises realizadas auxiliam para compreensão das possibilidades e desafios que os setores educativos enfrentam em sua conformação e aprofundam o entendimento da educação em museus como uma área de conhecimento.

\section{PALAVRAS-CHAVES:}

comunidade de prática; educação em museus; práticas educativas; setores educativos; museu de ciência.

\author{
Luciana M. Monaco * \\ Instituto Butantan \\ Martha Marandino ** \\ Universidade de São Paulo
}

The understanding of the education practice of a museum using the perspective of communities of practice ABSTRACT:

This paper discusses the dynamics of formation of the practices carried out by educators in the education sector in a science museum in the view of Communities of Practice by Etienne Wenger. The universe of study was the educational area of the Paraense Emilio Goeldi Museum and the data were analyzed based on the categories of mutual engagement, joint enterprise and shared repertoire. It was found that the education area of this museum is structured partly as a community of practice of museum education. This analyzes help to understand the possibilities and challenges that these sectors face in their conformation, and help to understand the education in museums as an area of knowledge.

\section{KEY-WORDS:}

community of practice; museum education; educational practices; educational sectors; science museum.

\footnotetext{
* Coordenadora do Núcleo de Difusão do Conhecimento, Centro de Desenvolvimento Cultural, Instituto Butantan luciana.monaco@butantan.gov.br

** Professora Associada da Faculdade de Educação da Universidade de São Paulo marmaran@usp.br
} 


\section{Introdução}

A busca pela compreensão da especificidade educativa em museus tem se tornado foco de muitos debates atuais, apontando a própria constituição das equipes educativas como elemento primordial à construção da identidade dessas instituições (Machado, 2009; Geenf, 2012'; Martins, 20 I I; Monaco, 20I3).

Os educadores, responsáveis por desenvolver, aplicar, avaliar e reconstruir ações e programas voltados a diferentes públicos elaboram uma maneira peculiar de trabalho em conjunto, muitas vezes como resposta às condições institucionais. Essa peculiaridade pode ser notada nas equipes em suas formas de se organizar, de se relacionar, de pensar na ação educativa e de responder às demandas e aos problemas de origens internas e externas (Bailey, 2003). Como afirma Martins (20I I):

As ações educativas criadas pelos educadores de museus ao longo dos anos adquiriram características específicas, moldadas não só pelas tipologias institucionais e de acervos, como também pelas demandas da sociedade na qual o museu se encontra inserido (Martins, 201 I:100).

Assim, o imbricado universo da educação museal pode ser analisado a partir de um panorama mais abrangente que considera o contexto no qual cada setor educativo se insere. Como aponta Macleod (200I:54), ao destacar a importância de não se restringir a reflexão sobre este tema apenas às funções mais imediatas dos educadores, "precisamos de uma visão amplificada da profissão [do educador] que se move além de definições baseadas em tarefas específicas realizadas dentro das paredes do museu".

No entanto, os estudos que se debruçam sobre a constituição das equipes educativas em museus não elucidam as relações entre os profissionais e nem como eles negociam seus significados em relação à prática que conduzem, ou ainda como constroem suas identidades em relação à equipe e à instituição (Tran, 2008).

O que há bem descrito acerca desses profissionais na literatura refere-se à preparação, destacando-se que em geral estes não recebem formação específica para desenvolver as suas funções e acabam aprendendo na prática conteúdos que lhe são exigidos ao assumirem esse posto (Ruge, 2008;Tran, 2008).

Marandino (2008) discute algumas estratégias adotadas para preparar esse profissional ${ }^{2}$, desde aquelas focadas prioritariamente nos conteúdos específicos de cada museu, até as mais dialógicas que os consideram como educadores/ comunicadores nesse processo.

Há ainda a exigência de que os educadores atuem em colaboração com equipes diversas como curadores, designers e museólogos, como elemento essencial para a execução de inúmeros projetos: exposições, conteúdos educativos para o site, materiais para professores, produtos comunicacionais de naturezas distintas, sempre com a intenção de tornar os conteúdos de cada ação propícios a seus diferentes públicos.

Pode-se afirmar que independente da tipologia do museu e da qualificação de seus educadores, o fazer educativo nesses locais é complexo e merece ser compreendido para além do foco exclusivo nas tarefas e procedimentos,

I GEENF Grupo de Estudos e Pesquisa em Educação não Formal e Divulgação em Ciências I Workshop Internacional de Pesquisa em Educação em Museus 2012 FEUSP, São Paulo. Disponível em http://www. geenf.fe.usp.br/v2/?p=823. Acessado em maio de 2014 .

2 Esse profissional pode ser designado por nomenclaturas diferentes nas várias instituições museais de acordo a linhas educativas assumidas como: educadores, monitores, condutores, animadores, mediadores, etc. 
pautando-se também na experiência, na ação, nos processos de pensamento e nas suas interdependências. Nessa lógica, a dimensão da prática museológica, que inclui a educação, é reflexiva, pois integra o conhecimento teórico às suas práticas cotidianas por meio da construção das identidades de seus atores (Macleod, 200I).

Ademais, a nova função social exigida dos museus, de ser um espaço democrático de inclusão sociocultural, forjou novas práticas educativas, que passaram a considerar a participação de sua audiência nesse processo, saindo da posição de contempladores passivos a agentes atuantes na construção de significados (Hoopper-Greenhill, 1994; Gruzmann Siqueira, 2007).

Esse panorama revela a densidade, a complexidade e os desafios da ação dos educadores de museus. Como então analisar a prática educativa nos museus de modo a contemplar suas particularidades e contribuir para compreensão da identidade do educador? Como, ainda, essa análise pode auxiliar na legitimação da área de educação em museus?

\section{Analisando a prática educativa sob uma nova abordagem: as comuni- dades de prática}

Uma alternativa para se compreender a singularidade da educação em museus se dá a partir da ideia de prática dentro da perspectiva de comunidades de aprendizes. Esta perspectiva desponta dos estudos sobre as relações entre indivíduos que partilham um interesse genuíno comum e se esforçam para apontar soluções criativas a problemas que enfrentam juntos.

O conceito de prática aqui utilizado tem por base a teoria das comunidades de práticas, a qual se ancora na ideia da aprendizagem como um fenômeno social e, portanto coletivo, que ocorre por meio do engajamento continuado em ações, práticas, eventos, que vão sendo negociados e renegociados pelos membros que compõe cada comunidade. Dessa forma, a comunidade constrói seus significados em relação a cada uma dessas práticas e ao seu funcionamento de maneira negociada, porém nem sempre consensual. É nessa perspectiva, apresentada na obra de Etienne Wenger, que esse artigo pretende discutir a especificidade educativa dos museus atuais e as características que definem a identidade dos educadores.

A abordagem da comunidade de prática propõe que a aprendizagem esteja focada e se oriente em função da natureza do conhecimento, do próprio saber e em quem conhece. Desse conceito partem quatro premissas iniciais que a sustentam (Wenger, 1998:4):

- A constatação de que todo ser humano é um ser social;

- O conhecimento compreendido como uma forma de competência em relação ao empreendimento que cada indivíduo ou grupo experimenta;

- O saber visto como participação na busca por tais empreendimentos, ou seja, engajar-se ativamente no mundo;

- O processo de significação entendido como a habilidade humana de experimentar o mundo e de se engajar nele e fazer disso algo significativo, o que em última estância seria o produto da aprendizagem.

O desdobramento dessas premissas seria, portanto, entender a aprendizagem como participação social. $O$ termo participação nesse caso, não se restringe a eventos específicos de engajamento em determinadas atividades, mas 
engloba o processo contínuo de ser um participante ativo nas práticas sociais das comunidades e na construção das identidades em relação a essas comunidades (Wenger, 1998).

Ao trazer a perspectiva das comunidades de prática para o espaço museal, se introduz a dimensão de aprendizagem não do ponto de vista individual, mas da instituição. Tomando como eixo essa reflexão, os museus constroem sua identidade como fruto do desenvolvimento de suas práticas que são partilhadas mutuamente entre as comunidades que deles fazem parte e, dessa forma, aprendem coletivamente.

Além de situar o significado de aprendizagem, E. Wenger inclui a participação do indivíduo numa prática qualquer não apenas como um observador, mas como um participante ativo na prática social das comunidades onde constrói sua identidade em relação a elas. Ou seja, o que se interpreta como participação molda não apenas o que cada um faz, mas também o que cada um é e como interpreta o que faz.

Ao participar de uma prática, o indivíduo se engaja nela e passa a vivenciar os significados relacionados a ela, ao mesmo tempo em que os renegocia a cada vez sob a influência mútua do mundo e do contexto. A prática de uma comunidade qualquer pode então ser compreendida como um conjunto de repertórios e de ferramentas, métodos, histórias, além de atividades relacionadas à aprendizagem e à inovação de conhecimentos específicos a esse ambiente (Snyder;Wenger, 2004).

Como então compreender a prática educativa que se realiza nos museus? Antes de se estabelecer do que se trata tal prática é necessário compreender bem o que são as comunidades de prática, considerando para isso o conceito integral, sem dissociar a prática do termo comunidade.

As "comunidades de prática são parte integral da nossa vida diária. Elas são tão informais e tão intricadas que raramente elas tornam-se explícitas, mas pela mesma razão elas são também familiares" (Wenger, 1998:07, tradução nossa). Ser membro de uma comunidade de prática implicaria em partilhar de suas práticas, significados e construir sua própria identidade em relação a ela.

As comunidades podem ser então delimitadas em função das atividades ou práticas específicas (rotinas, rituais, artefatos, símbolos, convenções e histórias) que definem seus limites de pertencimento, bem como a conformação de suas identidades (Wenger, 2000). Seus membros vivem em acordo e desacordo, em harmonia e desarmonia, e fazem o que deve ser feito para que o empreendimento em torno dessa comunidade seja alcançado.

A distinção na atuação de cada um nas diversas comunidades de prática de que fazem parte se dá por meio da sua participação na prática, ou seja, por meio do engajamento desigual nessas práticas, que envolve: o conhecimento sobre elas; o espaço que cada um tem para participar nelas; a negociação dos significados construídos no interior de cada comunidade, que diz respeito à compreensão mútua de que algo precisa ser interpretado por todos, levando em consideração as significações que o grupo traz sobre determinado assunto. Ao viver a prática como participante cada um constrói e negocia seus significados sob a influência mútua do mundo e do contexto.

O processo de negociação de significados, de uma maneira nova ou readequada a cada circunstância produz o engajamento entre as pessoas, estabelecendo vínculos em torno de uma prática comum, e, por conseguinte, formando-se 
comunidades de práticas. Isso não quer dizer que deva sempre existir acordo ou harmonia, mas o compartilhamento de um contexto social comum com práticas também comuns é uma premissa à existência dessas comunidades (Lee, 2007).

Sob esse olhar, é possível entender as equipes educativas dos museus como possíveis comunidades de práticas, com práticas peculiares que podem, a partir de um dado momento, ser compartilhadas. Além disso, adotar a ideia de participação dos educadores num conjunto de práticas como parte da negociação de significados e de construção de uma identidade profissional pode ajudar a elucidar as características da dimensão educativa dos museus.

Compreender o conceito associado ao termo comunidade de prática implica em identificar as dimensões que dão coerência ao desenvolvimento de uma prática. Tais dimensões são: o engajamento mútuo, o empreendimento conjunto e o repertório compartilhado (Wenger, 1998). Ao considerar esses três elementos é possível diferenciar grupos que apenas se unem em torno de uma tarefa qualquer, e aqueles que se engajam verdadeiramente num empreendimento onde a aprendizagem coletiva está presente e se reflete na prática que eles desenvolvem. Alguns aspectos desses elementos serão brevemente apresentados.

Engajamento Mútuo: refere-se à disponibilidade de colaborar com os outros independentemente de haver acordo ou não; onde a complementaridade das competências e a capacidade dos indivíduos de conectarem efetivamente seus conhecimentos com os demais estão presentes. Para que o engajamento se sustente é necessário haver interesses em comum e perfis complementares que partilhem histórias de aprendizagem, além da disponibilização de espaços de interação entre as equipes (físicos e virtuais). A realização de tarefas conjuntas e a disponibilidade em auxiliar os outros é também um fator associado à manutenção do engajamento entre os indivíduos. Só é possível negociar significados e desenvolver um conjunto de práticas se houver relação entre seus participantes. Desse modo, ao se analisar a formação das equipes educativas, seus interesses em comum e a maneira como elaboram suas práticas pode-se aferir o quanto cada grupo está engajado e têm objetivos em comum a perseguir.

Empreendimento conjunto: ao compartilhar a experiência, os participantes de uma comunidade elaboram recursos físicos e simbólicos e essa ação exerce um papel importante na emergência da coerência do grupo. Ao conceber de maneira livre, e não por imposição ou decreto, um produto ou a prática envolvida em suas ações e atitudes, a comunidade começa a dar um sentido de apropriação e de responsabilidade a tudo o que construíram juntos. Como parte desse processo, se estabelece o empreendimento conjunto e, ao mesmo tempo, surgem as questões de poder implicadas nesse relacionamento de responsabilização e de reconhecimento da importância do outro. $O$ empreendimento sempre assume uma dinâmica complexa que se reflete inevitavelmente na prática daquela comunidade, pois abrange desde preconceitos, interesses, poder, coerção e o lado inverso, que inclui a amabilidade, respeito, confiança, etc. Dessa forma, a resposta a esses elementos acontece no processo da própria prática e é sempre mediada pelos indivíduos, em função do que eles entendem ser a situação em que estão envolvidos. Ou seja, as respostas às condições estão associadas à interpretação do grupo e, até mesmo quando a prática de uma comunidade é moldada por forças externas, a realidade cotidiana desse grupo será produzida considerando os recursos e as restrições enfrentadas. $\bigcirc$ 
empreendimento se faz então no decorrer de todo esse processo. No entanto, deve-se considerar como essencial a negociação mútua dos significados frente às condições diversas, e somente por meio dessa configuração que a prática em curso poderá sofrer alterações. $O$ empreendimento que os educadores de museus estão envolvidos, por exemplo, engloba uma série de elementos como tornar conteúdos extremamente complexos em unidades mais compreensíveis aos diferentes públicos por meio de processos, estratégias e materiais ou, ainda, reconhecer a competência de seus pares nesse trabalho mútuo.

Repertório partilhado: é o conjunto de recursos físicos e simbólicos elaborados pela comunidade de forma partilhada e que contribuem para a coerência do grupo. Ao construir o empreendimento, os vários membros vão ajustando as diversas interpretações de suas ações, das condições em que se encontram e dos desafios que enfrentam. Num movimento diário e contínuo, os indivíduos concebem significados diversos entre si que se inter-relacionam e acabam por se unir e tornam-se coerentes à prática que exercem. É essa coesão que, por meio da negociação de significados, pode levar a uma compreensão do que é participar de forma competente nessa prática. Assim, o repertório poderá ser reutilizado na prática e em situações futuras de acordo com as necessidades do grupo. É importante frisar o caráter partilhado desses recursos. Os indivíduos devem sentir que contribuem para a sua construção, ou ao menos para a constituição do significado de seus elementos. Entretanto essa apropriação não ocorre de maneira intencional e sempre consciente, pois é um processo que se dá na prática, no decorrer dos relacionamentos de forma integral ao fazer coisas juntos. Apenas incorporar os aspectos como normas, procedimentos, rituais, símbolos, etc. não é suficiente para sustentar uma prática. É necessário ainda, garantir a possibilidade de participação dos indivíduos para que a resistência e/ou transformação do que existe seja viável, mesmo sob influência de forças adversas, como aquelas relacionadas ao poder.

Outro aspecto constituinte das comunidades de prática é a noção de identidade, e, será discutida aqui como complementar aos demais componentes apresentados. Ao introduzir o conceito de identidade, Wenger (1998) enfatiza duas ideias: o foco na pessoa, mas numa perspectiva social e; a expansão desse mesmo foco para comunidades de prática, chamando atenção aos processos mais amplos de identificação e de estruturas sociais.Assim,"construir uma identidade consiste em negociar os significados de nossas experiências como membros em comunidades sociais (Wenger, 1998: 145)".

Por conseguinte, a identidade para a teoria social de aprendizagem é um aspecto integral e inseparável da prática, da comunidade e da construção de significados. Sob esse prisma, se pretende evitar a dicotomia individual/social sem, no entanto, perder a distinção que cada uma dessas interpretações traz à compreensão de identidade (Wenger, 1998). Ela é, portanto socialmente produzida como uma experiência viva de participação numa comunidade social, funcionando, assim, como ligação entre o social e o individual."[A identidade] Serve como pivô, entre o social e o individual e, portanto, cada um pode ser falado em termos do outro (Wenger, 1998: I45)”.

Genericamente pode-se dizer que ser um membro numa comunidade de prática se traduz em assumir uma identidade como uma forma de competência. Ou seja, cada um sabe o que é pelo que lhe é familiar, inteligível, útil, negociável, mas também pelo que lhe é desconhecido, pelo não entendido, pelo não produtivo. A identidade pode então ser construída como experiência negociada e ser 
interpretada por cada um na sua definição de quem é e pela maneira como se experimenta por meio da participação.

Os elementos apresentados caracterizam as comunidades de práticas e foram adotados como categorias de análise da prática da área educativa de um museu de ciências naturais, o Museu Paraense Emílio Goeldi (Monaco, 20I3). A finalidade foi discutir, na perspectiva das comunidades de prática, os desafios e possibilidades enfrentadas pelos educadores deste museu ao se relacionarem e definirem seus papéis e atribuições institucionais, buscando assim uma reflexão sobre as especificidades da educação que ocorre nesses locais.

\section{Aspectos metodológicos}

Para compreender como um setor educativo pode se organizar, tomando como pressuposto a formação de comunidades de prática, optou-se por analisar a experiência da área educativa do Museu Paraense Emílio Goeldi (MPEG). Localizado em Belém, no estado do Pará, este museu pertence ao Ministério de Ciência, Tecnologia e Inovação do Brasil e foi selecionado por ser uma das instituições museológicas mais antigas do país e pela relevante experiência no desenvolvimento de ações voltadas à educação e à popularização da ciência.

Para esta pesquisa os dados foram coletados a partir de entrevistas com quatro educadores da área educativa do museu, da análise de documentos e da observação de algumas ações desenvolvidas por esta área. Neste artigo priorizamos os dados obtidos por meio das entrevistas, realizadas com base em um roteiro semiestruturado que buscou levantar não somente as práticas desenvolvidas pela área, mas como estas eram realizadas, caracterizando a participação de cada membro. Serão apresentadas algumas características gerais da área educativa desta instituição e, em seguida, será realizada a análise de suas ações a partir das categorias propostas na perspectiva das comunidades de prática.

\section{A área educativa do MPEG}

O MPEG, fundado em 1866, é um centro de referência em pesquisa nas áreas de biologia, ecologia e antropologia amazônicas que atua desde seus primórdios na interface com a divulgação científica (Sanjad, 2008).A área educativa do MPEG se constituiu nos anos de $1980 \mathrm{com}$ a Divisão de Museologia (DMU) que contava com uma equipe multidisciplinar das áreas de biologia, pedagogia, comunicação, artes plásticas, turismo e museologia, de cerca de seis pessoas. $O$ trabalho da equipe tinha a clara intenção de oferecer atividades educativas integradas pautadas na missão institucional, que aproximasse a pesquisa científica do público. Nessa fase, havia uma forte tendência a se trabalhar com a educação patrimonial, tanto nas comunidades fora de Belém, como no bairro da Terra Firme, local onde o campus de pesquisa do Museu Goeldi se instalou.

O grupo de educadores nessa época foi também responsável por iniciar as programações voltadas à escola, ao público espontâneo que visitava o Parque Zoobotânico que compõe o Museu, além de ações extramuros, sempre na interface com os pesquisadores do MPEG. $O$ conhecimento nas áreas de biologia (zoologia e botânica), ecologia e antropologia eram a base das inúmeras atividades que esses profissionais desenvolviam nesse período.

Ao longo de um processo de setorização, a DMU foi sendo desmembrada e deixou de existir. Frente às condições institucionais e ao comprometimento com outras atividades dentro da instituição, os antigos membros do DMU, com o passar do tempo, assumiram responsabilidades e programas diferentes e, para isso formaram equipes também distintas. 
A consolidação dessa mudança veio com criação da Coordenação de Comunicação e Extensão (CCE) que assumiu todo o gerenciamento das ações de comunicação e de educação, agregando a nova Coordenação em Museologia (CMU) sob seu guarda-chuva institucional. O papel institucional da CCE consta na portaria $n^{\circ} 803$, de 23 de outubro de 2006 que aprova o regimento interno do Museu e define a função de cada instância:

Supervisionar, coordenar e acompanhar as atividades desenvolvidas pelo Serviço do Parque Zoobotânico, Serviço de Comunicação Social em articulação com a Coordenação de Museologia e de Coordenação de Informação e Documentação; assessorar o diretor nos assuntos pertinentes à comunicação de conhecimentos e à divulgação de acervos científicos nas áreas de atuação do MPEG e sobre a Amazônia; propor e supervisionar a execução de programas, projetos e ações relativas à museologia, educação, comunicação, informação, documentação e parque zoobotânico; e presidir e convocar, mensalmente, órgão(s) colegiado(s) que venham a ser criados pelo diretor destinados a deliberação de assuntos pertinentes a Comunicação e Extensão do MPEG (D.O.U. 25/I0/2006).

Assim, as áreas de educação e museologia se organizam atualmente em espaços físicos distintos e atuam em diferentes frentes, que são: a Coordenação de Museologia (CMU), o Serviço de Educação e Extensão Cultural (SEC) e o Núcleo de Visitas Orientadas (NUVOP), organizadas hierarquicamente na Coordenação de Comunicação e Extensão (CCE). No organograma, o SEC e - NUVOP encontram-se sob a coordenação do CMU; no entanto, na prática, estas três equipes atuam de maneira independente e contavam na época das entrevistas respectivamente com seis, três e seis pessoas em cada equipe.

Em seguida iremos analisar as ações realizadas pelas três equipes educativas do MPEG à luz das categorias elencadas, focadas nas comunidades de práticas.

\section{O engajamento mútuo no setor educativo do MPEG}

Para analisar a categoria engajamento mútuo na área educativa do MPEG, foram trazidos dados referentes à história inicial deste grupo e como os educadores se envolveram em suas atividades. Nesta história é possível perceber a raiz comum entre as equipes do SEC e do NUVOP, já que a partir de 1982, ambos estavam juntos e desenvolviam as mesmas ações sob a coordenação da extinta DMU. Neste período havia um sentimento de dedicação e colaboração na equipe, revelado no trecho trazido pelo coordenador do NUVOP.

No início, eu e a Luiza começamos datilografando convites chamando as escolas para verem exposições. Era uma dificuldade, mas era uma equipe unida. Depois o lldo soube que a Universidade Federal do Pará estava fazendo um grande projeto na área de Educação em Ciências, foi então que ele chamou a Clara, pedagoga, ela nos ajudou a organizar um Serviço de atendimento às escolas. Ainda não se pensava em Serviço de Educação, mas, a Clara decidiu transformar a ideia inicial num projeto de apoio ao ensino junto com a Universidade Federal do Pará. (Educador 4).

Desde esse início os membros do DMU eram ativos e tinham a colaboração e o apoio do coordenador geral, como estímulo ao trabalho de todos. É interessante ressaltar a importância que os membros dão a essa fase e como se 
engajavam facilmente nas ações propostas numa época em todos começaram como estagiários, entre os anos de 1982 a 1985. A oportunidade positiva de começar numa instituição como o Museu Goeldi que agrega ciência e difusão é evidenciada na fala do educador do SEC, salientando que área educativa nesse período foi uma escola e um espaço de desafios e conquistas.

Passei [na Universidade Federal] com aquela ideia de vir fazer pesquisa, mas surgiu uma bolsa, um estágio na área de educação e, eu mesmo querendo fazer estudar répteis, principalmente cobras, eu vim para cá. Mas eu não queria trabalhar com educação porque eu não queria ser professor, (...). Então o que eu fiz? Eu aceitei. Eu aceitei, me sujeitei a vir para o Serviço de Educação, mas querendo, com olho na pesquisa. Com seis meses eu já fiquei maravilhado com esse setor e não quis sair nunca mais. Então o que eu queria fazer com répteis eu estudei e escrevi uma cartilha chamada, os Répteis da Amazônia, álbum para colorir (...). (Educador 2).

O começo da carreira foi um evento marcante na vida desses profissionais, o que mostra grande identificação com as atividades educativas propostas pela instituição.

A breve contextualização sobre como os membros atuais do SEC e NUVOP iniciaram suas atividades, ainda que de forma sucinta, auxilia na análise do engajamento mútuo entre os membros das equipes educativas. $O$ engajamento mútuo só é possível se houver um envolvimento de seus membros num objetivo comum frente ao qual negociam significados ao mesmo tempo em que se desenvolve a prática associada ao grupo. Neste sentido, na origem da constituição dessas equipes e do trabalho dos educadores envolvidos havia um objetivo comum - desenvolver atividades educativas com o público visitante - e, ao realizá-lo a equipe construía uma prática de educação no MPEG, algo muito próximo ao que se apresenta numa comunidade de prática.

Mesmo nos dias atuais, os membros das equipes educativas (os mesmos desde a origem) ainda guardam pelo Museu Goeldi extremo interesse e dedicação que os move na direção de dar continuidade ao trabalho educativo realizado. As falas a seguir de dois educadores de diferentes equipes, apresentam de forma explícita essa relação de trabalho pautada no sentimento de pertencimento e paixão pelo que fazem, o que reforça também a formação de uma identidade na relação institucional e no auto reconhecimento de ser um educador nesse contexto.

Eu chego geralmente aqui 7 da manhã se não for um pouquinho mais cedo e eu saio às 5 da tarde, almoço aqui nessa sala. Eu me dedico, entendeu. Eu me dedico ao trabalho e a outras pessoas. E eu sou nível médio. Então quando a gente vê uma pessoa que entra crua, sem essa experiência. $O$ que nós cavamos aqui! Por exemplo, não foi à toa que eu fui para 44 municípios para mostrar que o Museu precisaria sair daqui de dentro. E eram contra, as pessoas eram contra. (...) (Educador 2).

Eu tenho o maior orgulho mesmo de ser educadora e de ser a única pedagoga aqui nessa instituição centenária que eu amo de paixão.Amo meu trabalho e eu como educadora, o que me dá mais alegria, mais prazer é saber que eu estou conseguindo repassar, não é repassar, é transmitir a esses jovens que eu oriento e para esses professores: que ser educador com todas as barreiras, com todos os preconceitos que a gente sofre, é muito interessante. (Educador 4) 
O envolvimento afetivo é, sem dúvida, mola propulsora do engajamento, mas não garante que este ocorra de fato entre as equipes. A mudança na área educacional do MPEG a partir da última setorização ocorrida em 2006, levou, com o tempo, a uma nova maneira de organização do trabalho entre os membros. $O$ desmembramento físico e estrutural que ocorreu na época da criação dos atuais núcleos formou equipes autônomas, algo que pode ser notado nas falas dos educadores, como no exemplo a seguir:

Olha atualmente o Serviço de Educação está dividido em três Núcleos. E esses Núcleos, a dificuldade minha é que os três Núcleos estão separados. (...) Fisicamente, o que ocorre muitas vezes é que é problema de estrutura aqui dentro (...) (Educador 2).

Nos dias de hoje, embora haja grande identificação dos educadores com a missão e com o trabalho educativo do MPEG, nem sempre há negociação de significados e engajamento em um objetivo comum entre o SEC e o NUVOP, elementos chaves para a constituição de uma comunidade de prática. Por exemplo, no processo de concepção de novas exposições, uma tarefa que necessitaria de trabalho multidisciplinar e da compreensão partilhada das ações, os aspectos relacionados ao engajamento mútuo não foram identificados.

Porque eu já fui chefe desse setor e quando era chefe eu fundi os dois e trabalhava em conjunto, museologia e serviço de educação. A partir da vinda de outro chefe, eles foram trabalhando exclusivamente com exposições. (...) nós só somos chamados quando a exposição está praticamente pronta: "O que é que vocês vão fazer da exposição?" Então fica difícil é aquilo que eu falei, enquanto a gente não participa do processo de criação, a gente não se sente dono, a gente já pega o bonde andando, é mais difícil. Então eu já tentei mostrar que a gente tem que trabalhar do início, chamar umas pessoas, qual é o tipo de exposição, então chama e o serviço de educação acompanha. Isso acontece algumas vezes, mas não é uma prática da gente sentar todo mundo junto e discutir, que seria o ideal (Educador 2).

O educador aponta a falta de aproximação entre as áreas educativas na produção das exposições como um problema para sua prática, explicitando a separação do trabalho entre as equipes.

Para além da autonomia das ações realizadas hoje pelas equipes, há também aproximações. Ao analisar a enorme variedade de ações educativas desenvolvidas pela área educativa do MPEG, é possível verificar o princípio comum entre SEC e NUVOP, pois ambos apresentam elementos que aproximam as práticas que desenvolvem. É o caso das ações extramuros: cada grupo realiza um conjunto de atividades fora do espaço do Museu, em geral com escolas e professores, mas também com os grupos comunitários dos locais alvos dos programas.

Outro exemplo de aproximação entre os elementos que compõem a prática destas duas equipes pode ser identificado no programa educativo que utiliza as trilhas ecológicas e educativas do Parque Zoobotânico do MPEG. Esta estratégia educativa é usada com grupos de visitantes agendados e espontâneos tanto pelo SEC como pelo NUVOP.

Em algumas das ações apresentadas há evidências de conexões e mesmo de sobreposições entre os grupos que compõem a área educativa, mas ao analisar as ações específicas realizadas pelas equipes percebe-se que cada uma delas adota seu conjunto de repertórios de forma autônoma. Estas características nos levam a afirmar que a nova estruturação física e simbólica da área educativa 
promoveu mudanças profundas na maneira com que seus membros se relacionavam e na própria caracterização da prática educativa deste museu.

As tensões e os conflitos fazem parte das relações e estão contempladas na concepção das comunidades de prática. Contudo, o modo como esses enfrentamentos são tratados pelos indivíduos deve incluir, necessariamente, a possibilidade de negociação e de resignificação da prática em nome de um objetivo maior, dando vida ao engajamento. No caso do Museu Goeldi, as evidências apontam para uma mudança ao longo da história da área educativa, no que se refere ao modo com que os membros se envolvem nas ações que conduzem. A distância física e a não realização de atividades conjuntas indicam que as diferenças de opiniões, concepções e pontos de vista não são negociadas na forma como as equipes hoje se constituem. Esta conformação não promove encontros entre os diferentes atores e, de certa forma, diminui a capacidade criadora que pode emergir de grupos que passam por condições adversas de uma forma partilhada.

Em uma comunidade de prática, o enfrentamento, a demonstração e disputa pelo poder estão presentes, entretanto, somente quando o grupo responde de forma coesa a essas condições, um engajamento pode emergir e fomentar o estabelecimento de objetivos comuns, de inovações na prática do sistema educativo. Se as disputas por espaço, por reconhecimento, por interesses pessoais não são colocadas em um segundo plano e não permitem que o novo surja, não há como se consolidar qualquer engajamento e as comunidades acabam não se constituindo de fato.

\section{O empreendimento conjunto na experiência do setor educativo do MPEG}

O empreendimento comum é o resultado da negociação frente às condições que os indivíduos vivenciam de maneira cotidiana e que reflete a complexidade do engajamento mútuo. No processo vivo que se estabelece entre as pessoas ao se depararem com as mesmas restrições e aberturas, uma relação mútua de responsabilização entre os membros pode se estabelecer e tornar-se parte da prática.

No caso das equipes educativas do MPEG, verifica-se que há desafios comuns entre eles, como a falta de financiamento para o desenvolvimento das ações educativas. $O$ empenho dos educadores para conseguir recursos financeiros expõe o senso de responsabilidade das equipes em torno da finalidade comum de realizar atividades educativas com o público, missão primordial do setor

Quem financia é o Museu, (...) Então a gente faz a proposta diz "olha vai ter isso, isso e isso" vem do Tesouro, dos cofres do recurso do Museu para financiar as atividades que a gente faz. Quando não tem, a gente mesmo financia (Educador I).

Nossa instituição Museu aqui tem um peso muito grande, eu vou dar um exemplo. (...) Eu peguei o Clube do Pesquisador Mirim que tem 180 crianças, fiz uma reunião com os pais aqui no auditório e disse que a gente ia fechar. Alguns funcionários e bolsistas disseram "a gente vem trabalhar de graça esses 03 meses para poder segurar o projeto". Eu disse não. Se a gente fizer isso, a gente está solucionando um problema, a gente tem que jogar esse problema para outros. Então reuni as mães 
queriam fazer doce para vender, os pais queriam se cotizar para pagar o salário das pessoas, mas tudo implicava em não podia, porque eles estariam aqui 03 meses ganhando, mas sem seguro, era irregular. Conclusão, uma senhora que era secretária do governador, secretária de um secretário do governador, entrou em contato com o governador e o governador do estado bancou todos os salários durante esse período dos bolsistas estagiários, pagou seguro, tudo (Educador 2).

A disposição em conseguir recursos para financiar as ações leva não somente a equipe responsável a buscar meios para viabilizá-las, como também mobiliza aqueles sujeitos que atuam de forma periférica auxiliando nas atividades (bolsistas e funcionários) e os públicos que delas participam. Esta capacidade de mobilização do grupo em torno do financiamento revela a responsabilidade das equipes educativas em torno de um empreendimento, ou seja, o atendimento ao público.

O tema da biodiversidade, presente na missão institucional, é outro balizador de grande parte das ações educativas tanto do SEC quanto do NUVOP. Segundo consta em sua página institucional³, a missão do MPEG é: "Realizar pesquisas, promover a inovação científica, formar recursos humanos, conservar acervos e comunicar conhecimentos nas áreas de ciências naturais e humanas relacionados à Amazônia".

Quanto aos objetivos estratégicos para o período 20I I-2015, destacam-se aqueles voltados a consolidar e ampliar competências em CT\&I relacionadas à bio e sociodiversidade e consolidar o Museu Goeldi como um centro de pós-graduação na Amazônia, além de fortalecer a ação educativa no MPEG.

Portanto, nos programas e atividades das equipes educativas há um forte alinhamento com a missão do Goeldi.

Eu acho que a biodiversidade é que vai nortear muitos trabalhos que a gente faz aqui, até mesmo porque dentro da Amazônia isso é muito presente, essa riqueza que a gente tem aqui de espécies, e que muitas vezes são ainda desconhecidas. (...) E o Museu, eu acho que ele tem um papel importante nesse sentido, porque além dele atuar nessa parte de educação, também vai trabalhar com as pesquisas nessa área. Então a gente tem como subsídio a pesquisa que a instituição desenvolve na área de biodiversidade para informar ao público (Educador I).

Outro fator relacionado à visão institucional que os une é a autodescrição dos educadores como facilitadores ou canais de comunicação entre a pesquisa e os públicos atendidos, se responsabilizando fortemente com esse papel, e configurando-se como um elemento constituinte da identidade desse educador:"Porque aqui eu sirvo de canal de comunicação entre a pesquisa científica e esse público, esse professor, esse aluno que visita constantemente aqui a nossa instituição" (Educador 4).

Essa atribuição assumida pelos educadores traz um sentido de participação num projeto maior associado ao trabalho educativo, que os conecta as áreas de pesquisa da instituição e, novamente contribui para definir uma identidade parcialmente comum a todos que se expressa na intersecção institucional. De fato, há um efetivo trabalho em parceria construído ao longo dos anos entre muitos pesquisadores e as equipes educativas.

3 Disponível na página na internet do Museu Paraense Emílio Goeldi. http://www.museugoeldi.br/portal/ content/apresentaçao,. Consultada em maio de 2014. 
(...) a missão do Museu, que é a pesquisa, então eu não posso esquecer da Zoologia, da Botânica, das Ciências da Terra, tem que ter essa ligação e o pesquisador me repassa o resultado da pesquisa e a gente encaminha pra todos [envolvidos na ações] (Educador 4).

Essa aproximação entre as equipes em torno de uma mesma finalidade, qual seja, a comunicação da pesquisa realizada pelo MPEG para o público, torna a experiência desta instituição próxima à ideia de comunidades de prática, no que se refere ao empreendimento comum. Ademais, ao participarem como educadores e negociarem significados em relação à missão do MPEG, um processo de reconhecimento mútuo frente a essa negociação se faz, podendo desencadear simultaneamente a elaboração de uma identidade partilhada entre as equipes, ou seja, de reconhecerem-se como educadores. É verdade, contudo, que cada uma delas desenvolve ações específicas e de forma independente em torno da missão institucional. O NUVOP, por exemplo, realiza programas de ação educativa no Parque Zoobotânico para público escolar e geral, além de programas de formação de professores, de guias turísticos e de monitores. O SEC, por outro lado, desenvolve programas de formação científica para público escolar e programas relacionados ao desenvolvimento de recursos pedagógicos e museográficos. Já o CMU desenvolve exposições e recursos museográficos para o público geral, no entanto, toda a parte pedagógica associada a essa produção depende da orientação vinda das outras equipes. Essa forma de atuar das equipes educativas revela que cada uma delas encontra-se à frente de atividades e programas específicos que funcionam de maneira independente e raramente articulada. Não há, desse modo, um sentido de responsabilização coletivo em relação à manutenção de um objetivo comum, já que as negociações e resignificações sobre as ações que desenvolvem não são conduzidas entre os membros das equipes que formam a área educativa, mas somente internamente em cada grupo.

\section{O repertório partilhado pelos educadores no setor educativo do MPEG}

Conceber, elaborar executar as ações educativas é um processo comum a todas as equipes educativas do MPEG. Como vimos, atividades como as triIhas, as ações extramuros, a parceria com as escolas, as atividades de formação de professores, a elaboração de exposições e materiais didáticos, entre outras, compõem o conjunto de produtos e elementos da prática educativa dessas equipes.

Além de produzir ferramentas e recursos comuns, o repertório - que inclui rotinas, palavras, ferramentas, estórias, gestos, ações, conceitos, entre outros - do ponto de vista das comunidades de prática, necessita da participação dos indivíduos nessa prática ao mesmo tempo em que criam abstrações sobre os diferentes recursos, e que vão sendo internalizadas no grupo. Em todas essas representações (conceitos, estórias, palavras, etc.) os aspectos da experiência (humana) foram congelados em formas fixas e ganharam a partir daí, o status de objeto, ou como diz a teoria aqui utilizada, foram reificados.

A compreensão de que as abstrações podem se tornar coisas palpáveis ajuda a entender como os educadores do MPEG se relacionam com a atividade de trilhas, por exemplo. Para eles, essa ação, construída historicamente entre os grupos, é alvo de resignificações, e certamente de embates entre os grupos. 
Os educadores a elaboraram em função dos públicos, adotando conformações distintas em cada equipe.

No exemplo a seguir, a trilha foi pensada para o visitante espontâneo do Parque e não necessitou considerar os elementos dos conteúdos curriculares, e nem contar com a colaboração das escolas em sua execução.

Eu já fiz da Histórica, temos a trilha dos sentidos que eu já te falei, tem a Via Crucis, que é desde a captura de um animal na floresta até a morte, por quê? O cara captura um animal lá e o que acontece muitas vezes no Pará: captura o bicho, a pessoa compra não sabe cuidar ou o bicho morre, ou ele manda para o museu. No museu o bicho chega doente vai para um local, vai ser cuidado, tem muitas vezes que ele está tão doente que ele morre. Então a gente mostrava como se fosse aquela estação, as paradas que Jesus fez, mas como se fosse o espaço no Parque (Educador 2).

Já para o outro educador, pertencente à outra equipe, a proposta da trilha perpassa pela necessidade de parceria com a escola e pelo desafio de atender às demandas curriculares.

Ah, vamos fazer um roteiro [trilha] com a castanheira e a gente pensou, foi identificando essas espécies ao longo do Parque. Eu fiz as pesquisas, criando os textos e resumindo as informações. E a gente trabalhou nessa trilha com a escola, no caso o Ulisses Guimarães, a gente chamou, eu chamei os professores aqui, eu disse, olha a gente tem esse tema, a gente vai trabalhar essa trilha, a gente queria a parceria de vocês. Expliquei e eles foram lá, levaram para as escolas e trabalharam com os alunos deles a temática e nós montamos o roteiro da visita (Educador I).

Claramente, o recurso trilhas faz parte do repertório das equipes SEC e NUVOP e foram sendo reinventadas por seus membros de diferentes maneiras, dando origem ao conjunto de trilhas escolares e de trilhas para públicos espontâneos. Mesmo que muitas vezes essa ação tenha elementos muito similares, como as dramatizações, ao acontecerem em condições distintas por grupos que não partilham a mesma concepção, novas abordagens surgem, e associados a elas, uma nova prática pode também emergir.

Outro bloco de recursos utilizados por todas as equipes é a coleção didática, os jogos e os kits produzidos no âmbito do projeto Clube do Pesquisador Mirim, e, claro o espaço do Parque.

A relação com os pesquisadores é muito próxima e permite aos educadores lançar mão dos recursos da pesquisa, como no caso da própria coleção científica, e do espaço destinado à pesquisa, no campus fora do Parque, local onde ficam apenas as coordenações de pesquisa.

[...] Sim, a gente.., principalmente o Parque é a nossa referência, o espaço Raízes lá no centro perto dos bambuzais, agora também eu uso muito o auditório do Museu. Procuro pelo menos o Núcleo de Visita, a gente trabalhar nesse espaço aqui, mas devido ao nosso próprio trabalho, a gente usa muito o campus de pesquisa do Museu. E aquilo eu acho que no início quando eu falei do preconceito não por pesquisadores, que a gente tem muito de perto, eu tenho amigos pesquisadores, hoje em dia eles me procuram: "Laura, (...) não tem nenhuma palestra para eu dar?" Entendeu? Então a gente trabalha também aqui o Parque, mas o campus também, e o objeto a gente usa, procura, pelo menos quando tem exposição, a gente tem que trabalhar, passar isso para os professores, trabalhar sobre essa questão, até indígena (Educador 4). 
Embora as etapas de concepção, elaboração e execução das ações educativas sejam vivenciadas internamente por cada uma das equipes educativas do Goeldi, os seus membros, na maioria das vezes, não dividem entre si esse processo. Mesmo que a prática por detrás dessas ações seja de caráter similar, o seu desenvolvimento não é planejado coletivamente entre as equipes. $O$ compartilhamento se dá apenas no nível organizacional, como relata o educador:

Quando é uma coisa geral, planejamento geral, todo mundo, principalmente os funcionários com alguns bolsistas, (...) Existe o planejamento, as reuniões gerais, mas tem aquelas que são do grupo, por exemplo, a Luiza apoia o Clube do Pesquisador Mirim (CPM), mas ela não atua no CPM. Então quando se precisa da coleção aciona-se a Luiza, e ela apoia.A Joana e a Laura não atuam no CPM porque não têm perfil para o Clube, mas, por exemplo, quando tem algum evento elas participam, mas não é assim em função de ser em núcleos, cada um tem suas atividades então desenvolve e planeja em conjunto, a gente planeja o geral juntos, a gente fica sabendo o que está acontecendo, mas cada um toca o seu separado (Educador 2).

Ao observar o conjunto de repertórios das equipes educativas do MPEG pode-se notar novamente uma raiz comum, revelando que possivelmente os educadores estiveram engajados ao redor de um mesmo empreendimento, no início da história da área educativa, negociando e estabelecendo uma prática comum. Com o passar dos anos, o desmembramento, as alterações nas equipes e a perda da negociação entre os seus membros promoveram a manutenção de alguns recursos estabelecidos, mas que acabaram ganhando significados e representações distintas entre as equipes, conformando identidades específicas em cada grupo e alterando a prática que inicialmente era comum a todos.

\section{Discussão}

O funcionamento das equipes educativas estudadas, que compõem a Coordenação de Comunicação e Extensão do MPEG, sob a ótica das categorias analisadas - o engajamento mútuo, o empreendimento conjunto e o repertório partilhado - revelam como ora a área educativa deste museu se aproxima e ora se distancia da ideia de comunidades de prática.

Foi possível notar nesse estudo evidências de que no início da existência da área educacional deste museu houve o engajamento mútuo dos educadores, favorecido pela conformação que ela possuía, formada por uma equipe que trabalhava no mesmo espaço físico com objetivos comuns. Por meio das entrevistas percebeu-se que nesta fase inicial foi possível o estabelecimento de uma identidade de educador dentro da instituição, especialmente a partir da forma com que, em suas ações, estabeleciam relações de maneira partilhada.

A existência do engajamento mútuo entre os educadores se revela ainda a partir da forte relação afetiva com o trabalho e pelo vínculo institucional estabelecido ao longo de décadas de atuação na área educativa. Este panorama nos leva a afirmar que, no princípio de sua atuação, a experiência educacional no MPEG os aproximava fortemente da ideia de comunidades de prática educativa museal.

Com as mudanças ocorridas posteriormente, a partir da divisão em diferentes equipes - SEC, NUVOP e CMU - percebe-se que a perspectiva de engajamento mútuo não mais ocorre da mesma forma. $O$ trabalho conjunto no cotidiano institucional e a decorrente construção e reconstrução de significa- 
dos ao longo das atividades realizadas, que caracterizaria a constituição de uma comunidade de prática, não estão mais presentes ou são muito superficiais.

Do ponto de vista do empreendimento comum, é possível afirmar que o que hoje ainda os une é uma ideia partilhada do que é ser um educador dentro dessa instituição. É fato que existem ações educativas semelhantes ou próximas entre as equipes, quando, por exemplo, tomam por referência a pesquisa científica sobre biodiversidade desenvolvida no MPEG para a constituição de suas práticas. Essa aproximação, contudo, não caracteriza uma prática efetivamente compartilhada. Tais ações, mesmo que semelhantes, não têm objetivos comuns no sentido de algo que almejam e efetivamente planejam coletivamente.

O distanciamento físico entre as equipes e a pouca troca entre os membros dificulta a discussão, o planejamento conjunto e a solução coletiva de problemas, na qual o confronto poderia atuar como inovador da prática estabelecida. Assim, o que se vê é que as três diferentes equipes desenvolvem a sua prática e se relacionam com as demais práticas apenas nas conexões de caráter organizacional, como reuniões de planejamento, ou em tarefas específicas quando são chamados a trabalhar juntos.

O conjunto de repertórios partilhados pelos educadores passou pela mesma mudança ocorrida ao longo da história da área educativa no MPEG. Como apontado, houve um engajamento inicial onde o conjunto de práticas e produtos eram produzidos de modo compartilhado. Esta experiência se modificou com a separação das equipes e segue sendo isolado, havendo, contudo alguns elementos partilhados entre os educadores, como no caso do uso da trilha do Parque, atividades extramuros e o desenvolvimento e uso de jogos e kits de materiais educativos para suas ações. No entanto, estes não são mais resignificados pelos membros de forma coletiva; e não há oportunidade para construção de uma prática negociada. Por outro lado, cada educador conhece muito bem o repertório e ferramentas dos outros educadores e reconhece as competências de cada membro.

Os dados indicados revelam, por um lado, que a constituição de uma comunidade de prática não é algo absoluto e permanente ao longo do tempo. Dependendo da organização dos setores, da política institucional e da forma com que os educadores se relacionam, há uma dinâmica na formação dessas comunidades no tempo, podendo hora se constituírem efetivamente e hora se dissiparem (WENGER, 1998).

É importante destacar que o fato de um setor educativo de um museu não se caracterizar como uma comunidade de prática não implica em postular qualquer juízo de valor sobre a qualidade das ações educacionais realizadas por suas equipes. A experiência acumulada pelos educadores do MPEG e seu reconhecimento interno e externo revelam a relevância das ações educativas que realizam. No entanto, com base nos dados levantados, é importante refletir sobre as vantagens e desvantagens que a área educativa do MPEG teve ao se subdividir em setores e as implicações que esta conformação teve com relação ao engajamento coletivo dos educadores em torno de empreendimentos comuns e na produção de repertórios partilhados.

Segundo a teoria aqui adotada, ao se notar que certa prática precisa ser negociada, os membros compreendem a importância de cada um nesse transcurso, ou seja, passam a ver as competências individuais como complementares 
e se põem a serviço desse empreendimento. $O$ resultado desse vigoroso envolvimento é o que a teoria das comunidades de prática chama de aprendizagem social, na qual a descoberta e redescoberta de como fazer as coisas juntos dentro de uma mesma prática é uma questão central. Talvez exatamente por ter vivido a experiência coletiva de uma comunidade de prática no início de sua criação - e ter ocorrido efetivamente uma aprendizagem social - os educadores do MPEG reconheçam as competências e ferramentas usadas pelas equipes envolvidas e até hoje realizem práticas que os aproximam. A oportunidade de constituir comunidades de prática da educação em museus parece, assim, auxiliar no fortalecimento desta prática profissional, revelando as ações que une os profissionais deste campo e possibilitando o desenvolvimento qualitativo das mesmas.

Ao aplicar a teoria das comunidades de prática para compreensão da dinâmica dos setores educativos dos museus espera-se ampliar o debate em torno de questões centrais relacionadas à sua conformação. Este olhar faz emergir temas de fundo como a formação dos educadores, como eles se relacionam institucionalmente, como aderem ou não às demandas internas ou externas, como elaboram seus repertórios e como respondem coletivamente ao poder exercido institucionalmente. Muitos desses aspectos já foram estudados e evidenciaram, por exemplo, que os educadores são muito sensíveis ao público e que muitas vezes balizam a sua atuação em função da resposta deles (Tran, 2007; Machado, 2009; Martins, 20I I).

Entender se o conjunto de ações educativas desenvolvidas por um grupo profissional de educadores em uma instituição museal constitui ou não uma comunidade de prática possui o potencial de identificar, por um lado, as próprias ações que caracterizam esta prática. Por outro lado, auxilia no aprofundamento sobre como é realizada a prática educativa de um museu na busca de mapear o que a constitui e a distingue daquelas desenvolvidas em outros espaços educativos. Auxilia, por fim, a compreender melhor o caráter educativo dos museus.

Nessa direção, é possível afirmar que a identidade de um educador de museu não pode ser desconectada da missão institucional deste local. Assim sendo, a aprendizagem social e a formação desse profissional necessariamente passam pela experiência vivenciada de ser educador na instituição. Como afirmado anteriormente, o processo de tornar-se educador implica em realizar inúmeras escolhas e negociar posições internamente. No caso do Museu Goeldi, ser educador envolve o desenvolvimento de atividades com foco no público, em especial o escolar, mas envolve também tomar por base as pesquisas sobre biodiversidade no planejamento dessas ações. Além disso, implica agir com paixão e ter compromisso com a missão institucional, elementos essenciais que legitimaram a área educativa dentro e fora da instituição.

É na relação com o outro, na disposição em perseguir um objetivo que cada membro se vê competente e vai construindo individualmente a sua própria identidade. Mas também a constrói no coletivo, numa relação que se faz ao longo do tempo, nas histórias que cada um traz, na prática pré-existente, no sentido que cada um carrega de ser um membro de uma comunidade.

A composição das equipes educativas dos museus, sob a ótica das comunidades de prática mostra que muitos enfrentamentos podem ser encarados como oportunidades à negociação e à aprendizagem coletiva. Nessa perspectiva, para que um grupo de educadores integrem os conhecimentos específicos à 
prática educativa é necessário promover espaços de encontros, plataformas de comunicação, encorajamento de atitudes, sistematização das ideias por meio de registros e da troca de experiências resultantes desse convívio. Sem alimentar essa dinâmica, a negociação do que é ser um educador e perseguir um objetivo comum se tornará frágil e poderá até impedir que os grupos se vejam como pares e possíveis colaboradores.

No que tange à consolidação da função educativa dos museus e as especificidades de ser um educador, uma ação interessante é estimular a participação de seus membros em outras comunidades de práticas educativas de museus. Como nos conta Martins (20I I), os espaços construídos pela paulatina profissionalização dos educadores de museus desde a década de 1990 no Brasil, vem produzindo um crescimento deste campo intelectual, por meio da institucionalização da pesquisa acadêmica, do aumento de grupos de pesquisa sobre este tema junto ao CNPq, do crescimento de ações junto ao Comitê Internacional para Educação e Ação Cultural/CECA do ICOM e a Rede de Educadores de Museus, do surgimento de revistas na área e do Observatório de Museus e Centros Culturais. Este reconhecimento da área educativa dos museus como campo intelectual e produtor de conhecimento favorece a troca entre os profissionais, se constituindo como espaço onde se estabelecem as questões centrais e os temas de investigação na direção de buscar as referências para a prática e para sua formação.

Ao se facilitar os encontros entre indivíduos que partilham de um mesmo domínio e detêm um considerável sentimento de apreciação pelo seu trabalho, um movimento de reconhecimento mútuo pode se evidenciar, promovendo a validação conjunta desse importante campo de conhecimento que congrega profissionais das mais diversas áreas de formação inicial.

Pode-se afirmar ainda, tomando-se como base a ideia de comunidades de prática, que o reconhecimento da educação em museus como campo de conhecimento perpassa necessariamente pela negociação de uma identidade de educador para além dos limites institucionais e pela participação de seus membros em espaços ampliados de discussões como os fóruns, encontros, congressos, redes, associações, etc. É no encontro com outras práticas que pode ocorrer a convergência - mas também a divergência - promovendo o caminho na direção de objetivos comuns. É também nessa intersecção de experiências e reflexões que a legitimação da área de educação em museus pode se dar.

\section{Referências}

BAILEY, E. How museum educators build and carry out their profession: examination of situated learning within practice. Massachusetts. Dissertation (Doctor of Philosophy) - Lesley University, Cambridge, Massachusetts, 2003.

GRUZMANN, C.; SIQUEIRA, V. H. F. O papel educacional do Museu de Ciências: desafios e transformações conceituais. Revista Electrónica de Enseñanza de las Ciencias v. 6, n. 2, 402-423, 2007.

HOOPER-GREENHILL, Education, communication and interpretation: towards a critical pedagogy in museums. In: The Educational role ofThe Museum. Routledge, London, p. 3-25, 1994.

LEE, C. P. Reconsidering Conflict in Exhibition Development Teams. Journal of Museum Management and Curatorship v. 22, n. 2 183-199, 2007. 
MACHADO, M. I S.. O papel do setor educativo nos museus: análise da literatura (1987 a 2006) e a experiência do Museu da Vida.Tese (Doutorado) - Instituto de Geociências, Universidade Estadual de Campinas, 2009.

MACLEOD, S. Making museum studies: training, education, research and practice. Journal of Museum Management and Curatorship, v. I9, n. I, pp. 5I-6I, 200 I.

MARANDINO, M. O Mediador na Educação Não Formal: algumas reflexões. In: Caderno do Museu da Vida - I e II Seminários sobre o Formal e o Não Formal no Espaço dos Museus de Ciências. Rio de Janeiro: Museu da Vida - FIOCRUZ, p. 2631. 2002.

MARANDINO, M. (org.) Bizerra,A. F.; Navas,A.M.; Fares, D. C.; Standerski, L.; Monaco, L. M.; Martins, L.C.; Souza, M. P. C.; García, V. A. R. Educação em museus: a mediação em foco. São Paulo, SP, GEENF/FEUSP, 2008.

MARTINS, L. C. 20I I. A constituição da educação em museus: o funcionamento do dispositivo pedagógico museal por meio de um estudo comparativo entre museus de artes plásticas, ciências humanas e ciência e tecnologia.Tese (Doutorado) - Faculdade de Educação, Universidade de São Paulo, 20I I.

MONACO, L. M. O setor educativo de um museu de ciências: um diálogo com as comunidades de prática.Tese (Doutorado) - Faculdade de Educação, Universidade de São Paulo, 2013.

RUGE, A.Museum Professions:A European Frame of Reference. ICTOP. 2008. ICOM, Paris, 2008. Disponível em http://icom.museum/fileadmin/user_upload/pdf/professions/frame_of_reference_2008. SANJAD, N.A revitalização do Parque Zoobotânico do Museu Goeldi: em busca de uma nova relação com o público. Revista Museologia e Patrimônio, v. I, p. I23-I 27, 2008.pdf

SNYDER,W.;WENGER, E. OurWorld as a Learning System: a Communities-of-Practice Approach In: CONNER M. L., CLAWSON J. G. (eds). Create a Learning Culture: Strategy, Practice, and Technology. Cambridge University Press: p. I-18, 2004.

TRAN, L. U.; KING., H.The professionalization of museum educators: the case in the science museums. Museum Management and Curatorship v. 22, n. 2, I 3 I-I 49 , 2007.

The work of science museum educators. Museum Management and Curatorship v. 23, n. 2. 135-153, 2008.

WENGER, E. Communities of practice: Learning, meaning and identity. New York: Cambridge University Press, 1998.

Communities of practice and social learning systems. Organization, v.7, n. 2, p. 225-46, 2000. 
88

늠

ษั

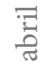

을

ڤ

$\exists$

띨

究

岁

宊

余

z

$\mathbb{4}$

웅

究 